\title{
Cohabitation, Marriage, and Men's Intimate Partner Violence Victimization
}

\author{
Douglas A. Brownridge* \\ Professor, Department of Family Social Sciences, Faculty Associate, Arthur V. Mauro Center for Peace and Justice, \\ Honorary Professor, University of Hong Kong, Hong Kong
}

\begin{abstract}
This study examines the elevated risk of intimate partner violence against men in cohabiting relative to marital unions using a large-scale representative survey of Canada. A theoretical framework is applied which distinguishes cohabiting and marital unions in terms of characteristics that select them into their union type and consequential characteristics of their relationships. Consistent with previous research on women's victimization, results show that selection (young age) and relationship (partner's jealousy, possessiveness, domination and alcohol abuse) variables account for cohabiting men's elevated risk of violent victimization. This suggests that as cohabitation becomes more normative in society, cohabitors will become a less select group and the risk of violence against cohabiting men will eventually converge with that of married men.
\end{abstract}

Keywords: Cohabitation, marriage, intimate partner violence, men.

\section{INTRODUCTION}

Relationships in which an unmarried couple lives together, also known as cohabiting unions, tend to have higher rates of intimate partner violence (IPV) compared to marital relationships (Anderson, 1997; Boba, 1996; Brinkerhoff \& Lupri, 1988; Jackson, 1996; Magdol, Moffitt, Caspi, \& Silva, 1998; Stets, 1991; Stets \& Straus, 1989). Most research that has delved into understanding "cohabitors" elevated risk of violence has focused specifically on women's victimization. For example, Brownridge (2008) has shown that a combination of factors which select individuals into cohabitation and factors specific to cohabitors' relationships account for the higher risk of violence against women in cohabiting relative to marital unions. Extant research begs the question of whether, as for women, selection and relationship factors account for the elevated risk of violence against men in cohabiting unions. The purpose of the current study, then, is to begin to fill this gap through examining cohabiting men's risk of intimate partner violence victimization relative to married men using data from a nationally representative sample of Canadians.

\section{THEORETICAL FRAMEWORK: THE SOCIAL CONSTRUCTION OF VIOLENCE IN COHABITING UNIONS}

One way to investigate higher rates of violence in cohabiting relative to marital unions is through an application of a theoretical framework that analytically distinguishes risk markers for violence in terms of whether they are characteristics that cohabitors tend to bring to their unions (selection

\footnotetext{
*Address correspondence to this author at 35 Chancellor's Circle, University of Manitoba, Winnipeg, MB, Canada. R3T 2N2, Canada; Tel: (204) 474-8050; Fax: (204) 474-7592;

E-mail: Douglas_Brownridge@umanitoba.ca
}

factors) or characteristics that tend to occur within the context of the union (relationship factors; Brownridge \& Halli, 2000). ${ }^{1}$ This theoretical framework is based on insights from Berger and Kellner's (1994) thesis of reality construction in marriage. According to these theorists, marriage is a nomosbuilding instrumentality in which the couples' lives become more stable through the unwitting construction of a new reality. As a result, through marriage two individuals unite, redefine themselves and, as Berger and Kellner (1994) wrote, "in the most far reaching sense of the word, the married individual "settles down"' (p. 29).

It is reasonable to argue that when two individuals begin to cohabit they too build a nomos together. However, if there are differences in the characteristics of people who choose to cohabit from those who choose to marry (selection factors), the objective reality that they construct may well be different, with ensuing consequences for their relationship (relationship characteristics). Based on past Canadian research (Brownridge, 2004, 2008; Brownridge \& Halli, 2001, 2002), factors such as youth, low education levels, unemployment, past unions, violence by previous partners, and residing in Québec, which has a much higher rate of cohabitation than the other provinces of Canada, may select individuals into cohabitation. These selection differences may, in turn, impact the relationship. For example, Kalmun and Bernasco (2001) found that those who cohabit tend to live more separated lives compared to those who marry. These researchers speculated that "couples who are cohabiting are less secure of their relationship and may therefore be more reluctant to develop a joint lifestyle" (p. 653). Lower security among cohabitors may lead to more compensatory domineering

\footnotetext{
'Several explanations for cohabiting women's elevated risk of violence have been identified. Interested readers may wish to refer to Brownridge and Halli (2001) and DeKeseredy, Alvi and Schwartz (2006).
} 
behavior, more sexually proprietary behavior, greater social isolation, a higher probability of depression, more heavy alcohol consumption, and a reduced likelihood of having children. These selection and/or relationship factors may then lead to more disagreements, conflict and violence. For example, conflict may occur if one member of the couple desires children and the other does not, and such disparate expectations are more likely to occur in cohabiting relationships (Ambert, 2005).

\section{PREDICTING TRENDS IN COHABITORS' RELATIVE RISK FOR VIOLENCE}

The social construction of violence is, by definition, not a static process. As cohabitation becomes more common, the characteristics of persons who choose to engage in such unions will tend to change. For example, based on Sweden's experience, which is the nation most advanced in terms of the development of cohabitation, Kiernan (2002) has identified four stages through which cohabitation progresses in a society. In the first stage, cohabitation is practiced by a minority of the single population and is seen as a deviant or avant garde phenomenon. In the second stage, cohabitation is a childless phase in which the couple tests their relationship for its marriage worthiness. In the third stage, cohabitors can become parents and cohabitation is seen as an acceptable alternative to marriage. Finally, in the last stage, cohabitation and marriage are indistinguishable, such that children are born and raised in cohabiting unions. Applying this view of cohabitation as a form of family life in transition draws one's attention to the fact that the characteristics of individuals who choose to cohabit will change over time. In the context of the theoretical framework outlined here, one would expect that as cohabitation in a society progresses toward the fourth stage of development, and hence becomes increasingly normative, the selection bias will be reduced. Consequently, the characteristics of cohabitors' relationships will become more like that of "marrieds" and the relatively higher rates of violence for cohabitors will become increasingly similar to that of marrieds.

\section{MATERIALS AND METHODS}

\section{The Data Set}

The data employed in this study were from Statistics Canada's General Social Survey (GSS) conducted in 1999. The GSS consisted of a random sample of 25,876 men and women who were age 15 years or older. Respondents completed in-depth telephone interviews concerning the nature and extent of their criminal victimization, including experiences of IPV. Because the current study concerned the elevated risk of violence against cohabiting men relative to married men, the subsample of heterosexual men who were married or living common-law at the time of the survey consisted of 6,707 men (5,791 married and 916 cohabiting) from the public use microdata file for the 1999 GSS. In all applicable analyses, the weighting scheme suggested by Statistics Canada was followed. ${ }^{2}$

${ }^{2}$ Because the data were not drawn from a simple random sample, it was necessary to weight the data so that the population was adequately represented. In an analysis of a subsample of the data, the weights provided with the data must be rescaled in a manner that preserves the variability of the original weights but that has an average value of 1 . This is accomplished by first calculating the average weight for the respondents in the analysis and then dividing each respondent's weight by this average. The resulting weighting factor is used in the analyses.

\section{Measurement}

Selection variables. Age referred to the respondent's age at the time of the interview. Education consisted of the respondent's education in years. Respondent's and partner's employment were measured with a question that referred to whether the main activity in the 12 months before the interview was working at a paid job or business (employed) or looking for work, caring for children, or doing housework (unemployed). Previous marriage or common-law union was measured by whether the respondent had ever been in a marital or common-law relationship with a person other than their current partner. Previous partner violence referred to whether the respondent had experienced physical or sexual violence by a previous partner in the 5 years before the survey. Culture was determined by whether the respondent lived within or outside of Québec.

Relationship variables. Duration of relationship was measured with a variable derived from the respondent's report of the year in which they became married or began living with their common-law partner. Sexual proprietariness was measured with the respondent's answers to two questions. The first asked the respondent if his partner was jealous and did not want him talking to other women. The second question asked the respondent if his partner demanded to know whom he was with and where he was at all times. Social isolation was measured with a variable asking the respondent to indicate whether his partner tried to limit his contact with family and friends. Dominance was measured with an item that asked the respondent if his partner prevented him from knowing about or having access to the family income, even if he asked. Depression referred to whether the respondent reported having used medication or drugs to help them get out of depression in the month before the interview. Heavy alcohol consumption was measured with a question that asked the respondent how many times in the month before the interview his partner had consumed five or more drinks on one occasion. The presence of children referred to whether or not the respondent reported children aged 0-14 were residing in the household.

Violence. Ten behavioral items from a modified version of the Conflict Tactics Scales (CTS) were used to measure violence (Straus, 1979). IPV was defined as acts of physical assault (having something thrown at you that could hurt; being pushed, grabbed, or shoved in a way that could hurt; being slapped; being hit with something that could hurt; being kicked, bit, or hit with a fist; being beaten; being choked; being threatened with or having a knife or gun used against the respondent), physical threat (being threatened to be hit with a fist or anything else that could hurt), and sexual assault (being forced into any sexual activity by being threatened, held down, or hurt in some way) perpetrated by the respondent's current marital or common-law partner within a specified time frame preceding the interview. Hence, if respondents reported having experienced any of the aforementioned forms of violence within the specified time frame preceding the interview they were coded as having experienced IPV. For the descriptive analysis of prevalence rates, violence was divided into less severe and severe categories.

\footnotetext{
${ }^{3}$ For a justification of the operational definition of culture, see Brownridge (2002).
} 
The items comprising less severe violence were: being physically threatened; having something thrown that could hurt; being pushed, grabbed or shoved; and being slapped. The items comprising severe violence were: being kicked, bit or hit with a fist; being hit; being beaten; being choked; being threatened with or having a knife or gun used; and being forced into any sexual activity. Two reference periods were used in the current study: 1-year and 5-year time frames.

\section{Method of Analysis}

To examine the prevalence of overall violence against cohabiting and married respondents, as well as to investigate risk factors by marital status, descriptive analyses were conducted using cross-tabulations with chi-square tests of significance. Logistic regression was used for the multivariate analyses. Logistic regression is an appropriate technique for predicting a dichotomous dependent variable from a set of independent variables. Where appropriate, $t$-tests were used to compare differences in odds ratios.

\section{RESULTS}

\section{Descriptive Analysis}

Violence by marital status. In terms of overall violence, cohabiting men had a higher prevalence than married men of reporting having experienced violence in both the year prior to the survey $(3.6 \%$ vs. $1.4 \% ; \mathrm{p}<0.01)$ and in the 5 years prior to the survey $(8.0 \%$ vs. $3.5 \%$; $<<0.01)$. Cohabiting men were also more likely than married men to report having experienced both less severe $(7.6 \%$ vs. $3.4 \%$; $p<0.01)$ and severe $(3.3 \%$ vs. $1.8 \% ; \mathrm{p}<0.01)$ violence in the 5 years prior to the survey.

Table 1. Selection and Relationship Factors by Marital Status (\%)

\begin{tabular}{|c|c|c|}
\hline Independent Variables & Cohabiting & Married \\
\hline \multirow{2}{*}{\multicolumn{3}{|c|}{$\begin{array}{l}\text { SELECTION VARIABLES } \\
\text { Man's Age }\end{array}$}} \\
\hline & & \\
\hline $15-34$ & 47.5 & 15.6 \\
\hline $35-54$ & 42.5 & 50.7 \\
\hline 55 and older & 10.0 & $33.7 * * *$ \\
\hline Less than high school & 20.9 & 22.0 \\
\hline High school & 15.4 & 15.1 \\
\hline Some post secondary & 15.6 & 12.1 \\
\hline Community college diploma/certificate & 31.1 & 27.2 \\
\hline Worked past year & 95.6 & 96.9 \\
\hline \multicolumn{3}{|l|}{ Partner's Employment } \\
\hline Did not work in past year & 22.0 & 33.3 \\
\hline Worked past year & 78.0 & 66.7 \\
\hline \multicolumn{3}{|l|}{ Previous Marriage/Common-law Union } \\
\hline Yes & 47.6 & 14.0 \\
\hline No & 52.4 & $86.0 * * *$ \\
\hline \multicolumn{3}{|l|}{ Previous Partner Violence } \\
\hline Yes & 21.2 & 14.2 \\
\hline Less than 4 years & 32.5 & 16.4 \\
\hline $4-9$ years & 25.6 & $76.8 * * *$ \\
\hline 10 or more years & & \\
\hline
\end{tabular}


Table 1. cond...

\begin{tabular}{|c|c|c|}
\hline Independent Variables & Cohabiting & Married \\
\hline \multicolumn{3}{|l|}{ Partner's Jealousy } \\
\hline Yes & 13.5 & 6.3 \\
\hline No & 86.5 & $93.7 * * *$ \\
\hline \multicolumn{3}{|l|}{ Partner Know Whereabouts } \\
\hline \multicolumn{3}{|l|}{ Partner Limits Contact } \\
\hline Yes & 3.5 & 2.7 \\
\hline No & 96.5 & 97.3 \\
\hline \multicolumn{3}{|l|}{ Man's Depression } \\
\hline Yes & 2.2 & 3.0 \\
\hline No & 97.8 & 97.0 \\
\hline \multicolumn{3}{|c|}{ Partner's heavy drinking (past month) } \\
\hline None & 81.7 & 91.9 \\
\hline Once & 9.1 & 4.1 \\
\hline 2-4 times & 7.0 & 3.5 \\
\hline 5 or more times & 2.1 & $0.6 * * *$ \\
\hline
\end{tabular}

$* * \mathrm{p}<0.05 ; * * * \mathrm{p}<0.01$ ( $\mathrm{p}$ values refer to Chi-square tests of significance)

Risk factors by marital status. Table $\mathbf{1}$ contains the results of the cross-tabulations of the selection and relationship factors by marital status. With respect to selection factors, the results in Table $\mathbf{1}$ showed that cohabiting men were more likely to be young compared to married men. Nearly half of cohabiting men were under age 35 compared to about $16 \%$ of married men. Cohabiting and married men also differed with respect to education, with cohabiting men being less likely than married men to have a university degree (17\% vs. $23.6 \%$ ). Cohabiting men were also much more likely to have had a previous marriage or common-law union. Nearly half (47.6\%) of cohabiting men had previously been in a marital or common-law union compared to $14 \%$ of married men. Finally, a disproportionate number of cohabitors lived in Québec. Nearly half (47.4\%) of all cohabiting men in Canada lived in Québec and about one-fifth (20.7\%) of married men in Canada lived in Québec.

In terms of relationship variables, cohabiting men were much more likely to have short duration relationships compared to married men. About $42 \%$ of cohabiting men had been in their relationship for less than 4 years, compared to approximately $7 \%$ of married men. Cohabiting men were also more likely than married men to report that their partner was jealous and did not want them talking to other women
$(13.5 \%$ vs. $6.3 \%)$ and that their partners insisted on knowing who they were with and where they were at all times $(9.3 \%$ vs. 5.6\%). As well, cohabiting men were more likely than married men to report that their partners consumed alcohol heavily. Cohabiting men's partners were 3.5 times more likely to have abused alcohol heavily 5 or more times in the month prior to the survey $(2.1 \%$ vs. $0.6 \%)$. Finally, cohabiting men were slightly more likely than married men to have children under age 15 living in the home (38.7\% vs. $35.2 \%)$.

\section{Multivariate Analysis}

Separate logistic regressions. To identify the impact of each selection and relationship variable on the odds of violence against cohabiting and married men, separate logistic regressions were performed for each group. The results of these analyses are presented in Table $\mathbf{2}$. As shown in Table $\mathbf{2}$, holding all other variables constant, there were two selection variables that impacted men's odds of experiencing violence. Men's age had a similarly strong effect on their odds of experiencing violence for both the cohabiting and married groups. For each additional year older cohabiting and married men were, their odds of violence were reduced by $8 \%$ and $5 \%$ respectively. As well, men with unemployed part- 
Table 2. Results of Logistic Regressions on 5-Year Prevalence of Violence for Marrieds and Cohabitors

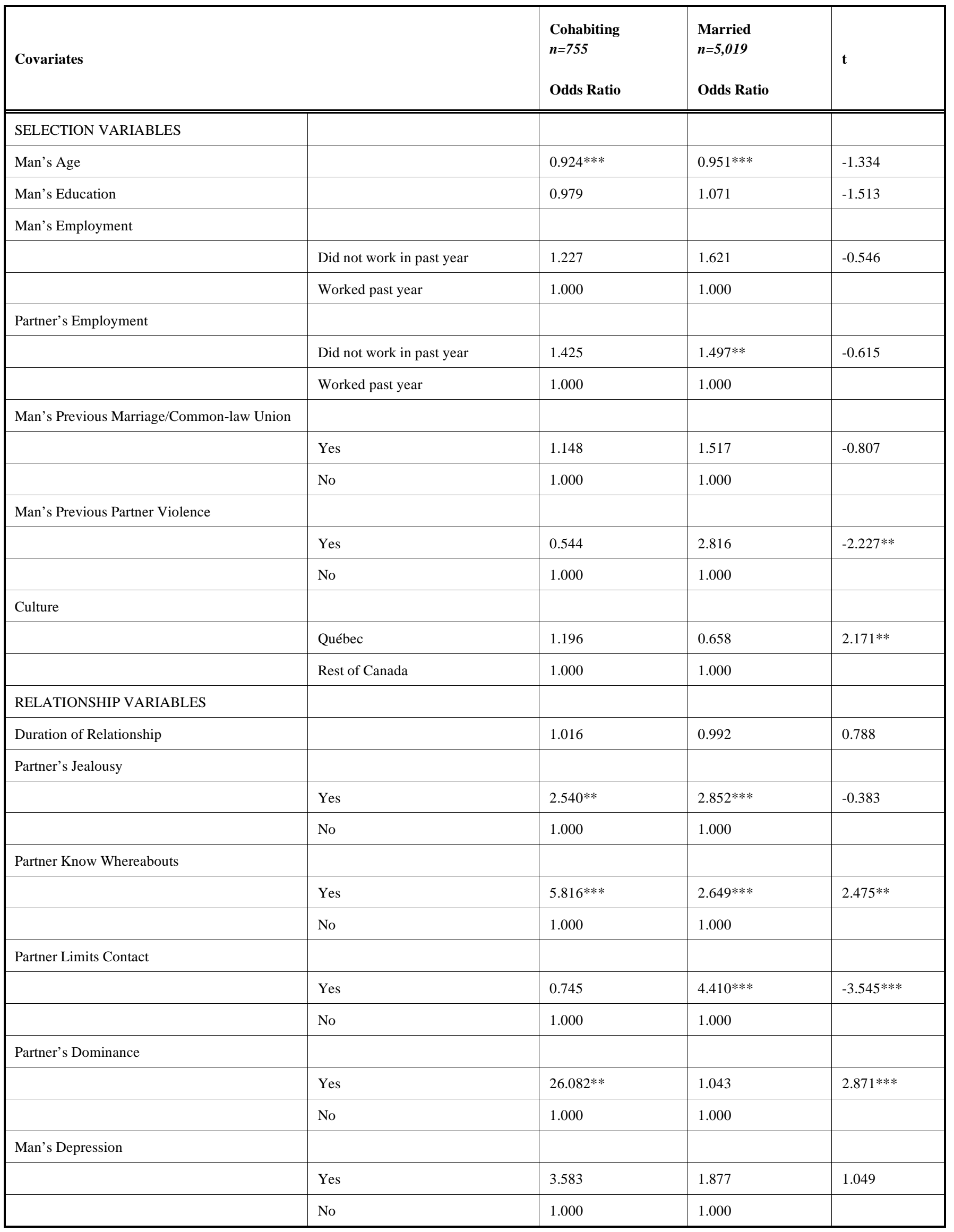


Table 2. cond...

\begin{tabular}{|c|c|c|c|c|}
\hline Partner's Heavy drinking & & $1.176^{* *}$ & $1.192 * * *$ & -0.247 \\
\hline \multicolumn{5}{|l|}{ Children < 15} \\
\hline & No & 1.000 & 1.000 & \\
\hline Constant & & 0.662 & $0.052 * * *$ & \\
\hline-2 Log likelihood & & 323 & 1,282 & \\
\hline
\end{tabular}

$* * \mathrm{p}<0.05 ; * * * \mathrm{p}<0.01$

ners had higher odds of experiencing violence than those whose partners were employed. Married men with unemployed partners had $49.7 \%$ greater odds of violence and cohabiting men with unemployed partners had $42.5 \%$ greater odds of violence. The $t$-test showed that these odds ratios were not significantly different from one another. ${ }^{4}$

With respect to relationship variables, all else equal, jealousy had a similarly strong impact on the odds of violence against cohabiting and married men. Cohabiting men with jealous partners had $154 \%$ greater odds of reporting having experienced violence and married men with such partners had $185 \%$ greater odds of reporting having experienced violence. Having a partner who insisted on knowing men's whereabouts also increased the odds of violence against both cohabiting and married men. However, the $t$-test showed that these odds ratios were significantly different from one another. Cohabiting men with partners who insisted on knowing their whereabouts had $482 \%$ greater odds of experiencing violence and married men with such partners had $165 \%$ greater odds of having experienced violence compared to their counterparts without such partners. Having a partner who limited men's contact did not have a significant effect on cohabiting men's odds of experiencing violence, but married men with such partners had $341 \%$ greater odds of violence. Conversely, while partners' dominating behavior did not impact the odds of violence against married men, cohabiting men whose partners prevented them from having access to the family income had much higher odds of experiencing violence than their counterparts without such partners. Heavy alcohol consumption had a similarly strong positive impact on the odds of violence against both cohabiting and married men. Each additional occasion in the month prior to the study that a man's partner abused alcohol was associated with an $18 \%$ increase in the odds of violence against cohabit-

\footnotetext{
${ }^{4}$ Although the effect of this variable for cohabiting men was not significant, the $t$-test showed that the odds ratio was not significantly different from the odds ratio for married men. Given the significant effect of this variable for married men, it is likely that the failure of this variable to be statistically significant for cohabiting men was due to the smaller subsample of these men. Hence, the odds ratio was interpreted as a substantively meaningful effect.
}

ing men and a $19 \%$ increase in the odds of violence against married men. Finally, the presence of children was associated with increased odds of violence against both cohabiting and married men (64\% and 55\%, respectively).

Sequential logistic regressions. Table 3 provides the results of the sequential logistic regressions on the 5-year prevalence of violence for cohabitors and marrieds. In these regressions, the first model contained only the marital status variable without any controls. In the second model, the marital status variable was entered along with the selection variables. In the third model the marital status variable was entered along with the relationship variables. In the fourth model, the marital status variable was entered along with both the selection and relationship variables.

As shown in Table $\mathbf{3}$, the difference in prevalence of violence against cohabiting relative to married men resulted in cohabiting men having $137 \%$ greater odds of experiencing violence in the 5-years prior to the survey. Controlling for selection variables (the second model in Table 3 ) reduced cohabiting men's odds of experiencing violence to being only $7 \%$ greater than married men, a difference that was not statistically significant. Similarly, controlling for relationship variables (the third model in Table 3) reduced cohabiting men's relative odds of violence to being only $5 \%$ greater than married men's odds. Controlling for both selection and relationship variables (the fourth model in Table 3 ) reduced cohabiting men's odds of experiencing violence to being only $3 \%$ greater than those of married men.

\section{DISCUSSION}

Consistent with past studies which indicated that cohabitors in general have a higher risk of violence than marrieds (Anderson, 1997; Boba, 1996; Brinkerhoff \& Lupri, 1988; Jackson, 1996; Magdol, et al., 1998; Stets, 1991; Stets \& Straus, 1989), the current study found that cohabiting men have an elevated risk of experiencing IPV compared to married men. Cohabiting men's elevated risk of violence was evident in both the 1-year and 5-years prior to the survey, and it existed when examining both less severe and severe violence. 
Table 3. Sequential Logistic Regressions on the 5-Year Prevalence of Violence

\begin{tabular}{|c|c|c|c|c|}
\hline & $\begin{array}{l}\text { Model } 1 \\
\text { Marital Status } \\
\mathrm{n}=\mathbf{6 , 3 4 3}\end{array}$ & $\begin{array}{l}\text { Model } 2 \\
\text { Selection } \\
\mathbf{n = 6 , 1 0 2}\end{array}$ & $\begin{array}{l}\text { Model } 3 \\
\text { Relationship } \\
\mathbf{n = 5 , 8 4 0}\end{array}$ & $\begin{array}{l}\text { Model } 4 \\
\text { Full Model } \\
\mathbf{n = 5 , 7 7 4}\end{array}$ \\
\hline Covariates & Odds Ratio & Odds Ratio & Odds Ratio & Odds Ratio \\
\hline \multicolumn{5}{|l|}{ Marital Status } \\
\hline Cohabiting & $2.370 * * *$ & 1.066 & 1.048 & 1.033 \\
\hline \multirow[t]{3}{*}{ Married } & 1.000 & 1.000 & 1.000 & 1.000 \\
\hline & & BLOCK & & BLOCK \\
\hline & & & BLOCK & BLOCK \\
\hline Constant & $0.037 * * *$ & 0.475 & $0.042 * * *$ & $0.157 * *$ \\
\hline -2 Log-likelihood & 2,157 & 1,927 & 1,693 & 1,640 \\
\hline$\chi^{2}$ & $31 * * *$ & $188^{* * *}$ & $379 * * *$ & $404 * * *$ \\
\hline
\end{tabular}

$* * \mathrm{p}<0.05 ; * * * \mathrm{p}<0.01$

Cohabiting men differed from married men on a number of selection and relationship factors which were theorized to account for their elevated risk of experiencing IPV. Similar to past research on cohabiting women's elevated risk of violence (Brownridge, 2008), results showed that these selection and relationship factors accounted for cohabiting men's elevated odds of experiencing violence compared to married men. Thus, the theoretical approach suggesting that the elevated risk of violence against cohabitors is a socially constructed consequence of selection and relationship differences between cohabitors and marrieds appears to be applicable to both female and male violent victimization. Because the theoretical framework is relevant to cohabitors in general, it was important to test it against male violent victimization in addition to female violent victimization. ${ }^{5}$ The finding that this framework accounts for both male and female violent victimization lends further support to the validity of this framework.

An examination of the results in the current study also allows some discussion of which selection and relationship variables accounted for cohabiting men's elevated odds of

\footnotetext{
${ }^{5}$ The most contentious issue in the literature on IPV concerns the debate over gender symmetry. Some research finds that males and females perpetrate violence at fairly equal rates while others report that the vast majority of perpetrators are male (cf. Kurz, 1989). It has been suggested that these contradictory findings are largely the result of the types of samples from which the data were derived. For example, Straus (1990) indicated that research based on representative samples tends to find gender symmetry and studies that employ clinical samples tend to find greater male perpetration. Research also suggests that results with respect to gender and IPV will vary across nations depending on the extent of gender equality within a given nation and the extent to which a given nation is individualistic or collectivistic (Archer, 2006). Countries which are higher on the continuum of women's relative equality to men and which are individualistic tend to have higher rates of female perpetration of IPV compared to nations that are lower on the equality continuum and which are collectivistic. Archer explained this using social role theory. That is, with greater equality and individualism, women become more agentic (i.e., stereotypically masculine), which includes the use of direct aggression. Given that Canada, the national context of the current study, is a country where women are relatively gender empowered and Canadian culture is on the individualistic end of the continuum, based on the insights identified above one would expect to see that both women and men would report being victims of IPV in a representative sample of Canada. Indeed, a cross-tabulation of sex by violence showed significant differences in the rate of reporting violent victimization in neither the 1-year $($ male $=1.7 \% ;$ female $=1.7 \% ; \mathrm{p}=0.992)$ nor the five-year $($ male $=4.2 \%$; female $=$ $3.7 \% ; \mathrm{p}=0.205)$ time frames.
}

violence. The sequential logistic regressions indicated that controlling for the selection variables accounted for cohabiting men's elevated odds of experiencing violence. The separate logistic regressions for cohabiting and married men showed that the only selection variable that had a significant impact on cohabiting men's odds of experiencing violence was age. Age had a similarly strong negative effect on cohabiting and married men's odds of experiencing violence. However, the descriptive analysis showed that cohabiting men were much more likely than married men to be young. It is conventional in Canadian society for partners in a couple to be of the same age or for the male partner to be slightly older (Eshleman \& Wilson, 1998; Martin-Matthews, 2000). Thus, cohabiting men's partners are likely to be younger than married men's partners. It would appear, then, that the disproportionate representation of young persons among cohabitors can account for cohabiting men's elevated risk of experiencing violence.

The results of the sequential logistic regressions also showed that relationship factors accounted for cohabiting men's elevated odds of experiencing violence. A number of relationship variables had a significant effect on cohabiting men's odds of experiencing violence. Like the selection factor of age, partner's jealousy and partner's alcohol abuse had a strong positive effect on both cohabiting and married men's odds of violence. Also, as with age, the descriptive analysis showed that cohabiting men's partners were more likely than married men's partners to be jealous and to abuse alcohol. Cohabiting men's partners were also more likely than married men's partners to insist on knowing their whereabouts, and this relationship variable had a stronger effect on cohabiting than married men's odds of experiencing violence. Although the aforementioned variables had effects on violence independent of one another, the finding from the sequential logistic regressions that both the selection and relationship factors accounted for cohabiting men's elevated odds of violence suggests that there may be a common element between them. That is, it appears possible that the younger age of cohabitors is linked to the greater tendency for these men's partners to be jealous, possessive and 
to engage in heavy alcohol consumption. This is consistent with the theoretical framework of the study, which purports that differential selection contributes to relationship differences between cohabiting and married couples.

Additionally, although cohabiting men's partners were not significantly more likely than married men's partners to dominate them by preventing access to the family income, this variable was associated with a large increase in cohabiting men's odds of violence. It is possible that the link between the measure of dominance and cohabiting men's violent victimization from an intimate partner is a result of issues around the pooling of income in cohabiting relationships. That is, while both members of a married couple have a right to use family assets (Ward, 2006), in cohabiting unions there is a relative lack of norms for income-sharing. So, sharing income may be a more common source of conflict in cohabiting unions.

In general, the results of the current study are in agreement with the previous research examining cohabiting women's elevated risk of IPV (Brownridge, 2008). That is, it appears that the elevated risk of violence against cohabiting men is a result of cohabitors being a select group (particularly young age), with consequent effects on characteristics of their relationships (partner's jealousy, possessiveness, domination, and alcohol abuse). This finding also suggests the same conclusion reported in past research with respect to predicting trends in cohabiting women's relative risk of violence (Brownridge, 2008). That is, as cohabitation becomes more normative in society, cohabitors will become a less select group and rates of violence against men in cohabiting relationships will eventually more closely approximate those of marital unions.

\section{REFERENCES}

Ambert, A.-M. (2005). Cohabitation and marriage: How are they related? Ottawa: The Vanier Institute of the Family.

Anderson, K. L. (1997). Gender, status, and domestic violence: An integration of feminist and family violence approaches. Journal of Marriage and the Family, 59(3), 655-669.

Archer, J. (2006). Cross-cultural differences in physical aggression between partners: A social-role analysis. Personality and Social Psychology Review, 10(2), 133-153

Berger, P., \& Kellner, H. (1994). Marriage and the construction of reality: An exercise in the microsociology of knowledge. In Handel, G. \& Whitchurch, G. G. (Eds.), The psychosocial interior of the family ( $4^{\text {th }}$ ed., pp. 3-17). New York: Aldine de Gruyter.

Boba, R. L. (1996). Violence between married and unmarried cohabiting partners: An analysis using couple-level data. Unpublished doctoral dissertation, Arizona State University.

Brinkerhoff, M. B., \& Lupri, E. (1988). Interspousal violence. Canadian Journal of Sociology, 13(4), 407-434.
Brownridge, D. A. (2002). Cultural variation in male partner violence against women: A comparison of Québec with the rest of Canada. Violence Against Women, 8(1), 87-115.

Brownridge, D. A. (2004). Understanding women's heightened risk of violence in common-law unions: Revisiting the selection and relationship hypotheses. Violence Against Women, 10(6), 626-651.

Brownridge, D. A. (2008). The elevated risk for violence against cohabiting women: A comparison of three nationally representative surveys of Canada. Violence Against Women, 14(7), 809-832.

Brownridge, D. A., \& Halli, S. S. (2000). "Living in sin" and sinful living: Toward filling a gap in the explanation of violence against women. Aggression and Violent Behavior, 5(6), 565-583.

Brownridge, D. A., \& Halli, S. S. (2001). Explaining violence against women in Canada. Lanham, MD: Lexington.

Brownridge, D. A., \& Halli, S. S. (2002). Understanding male partner violence against cohabiting and married women: An empirical investigation with a synthesized model. Journal of Family Violence, 17(4), 341-361.

DeKeseredy, W. S., Alvi, S., \& Schwartz, M. D. (2006). An economic exclusion/male peer support model looks at "wedfare" and woman abuse. Critical Criminology, 14(1), 23-41.

Eshleman, J. R., \& Wilson, S. J. (1998). The family ( $2^{\text {nd }}$ Canadian ed.). Scarborough: Allyn and Bacon.

Jackson, N. A. (1996). Observational experiences of intrapersonal conflict and teenage victimization: A comparative study among spouses and cohabitors. Journal of Family Violence, 11(3), 191-203.

Kalmun, M., \& Bernasco, W. (2001). Joint and separated lifestyles in couple relationships. Journal of Marriage and Family, 63(3), 639-654.

Kiernan, K. (2002). Cohabitation in Western Europe: Trends, issues, and implications. In Booth, A. \& Crouter, A. C. (Eds.), Just living together: Implications of cohabitation on families, children, and social policy (pp. 3-31). Mahwah, NJ: Lawrence Erlbaum Associates.

Kurz, D. (1989). Social science perspectives on wife abuse: Current debates and future directions. Gender \& Society, 3(4), 489-505.

Magdol, L., Moffitt, T. E., Caspi, A., \& Silva, P. A. (1998). Hitting without a license: Testing explanations for differences in partner abuse between young adult daters and cohabitors. Journal of Marriage and the Family, 60(1), 41-55.

Martin-Matthews, A. (2000). Change and diversity in aging families and intergenerational relations. In Mandell, N. \& Duffy, A. (Eds.), Canadian families: Diversity, conflict, and change ( $2^{\text {nd }}$ ed., pp. 323-360). Toronto: Harcourt Brace.

Stets, J. E. (1991). Cohabiting and marital aggression: The role of social isolation. Journal of Marriage and the Family, 53(3), 669-680.

Stets, J. E., \& Straus, M. A. (1989). The marriage license as a hitting license: A comparison of assaults in dating, cohabiting, and married couples. Journal of Family Violence, 4(2), 161-180.

Straus, M. A. (1979). Measuring intrafamily conflict and violence: The Conflict Tactics (CT) scales. Journal of Marriage and The Family, 4l(1), 75-88.

Straus, M. A. (1990). Injury and frequency of assault and the "representative sample fallacy" in measuring wife beating and child abuse. In Straus, M. A. \& Gelles, R. J. (Eds.), Physical violence in American families: Risk factors and adaptations to violence in 8,145 families (pp. 75-91). New Brunswick, NJ: Transaction.

Ward, M. (2006). The family dynamic: A Canadian perspective $\left(4^{\text {th }}\right.$ ed.). Toronto, ON: Nelson. 